\title{
Biodegradation of polycyclic aromatic hydrocarbons by Pichia anomala
}

\author{
Feng Pan ${ }^{1,2}$, Qingxiang Yang ${ }^{1,2}$, Yu Zhang ${ }^{1}$, Shujun Zhang $^{1} \&$ Min Yang ${ }^{1, *}$ \\ ${ }^{1}$ State Key Laboratory of Environmental Aquatic Chemistry, Research Center for Eco-environmental Sciences, \\ Chinese Academy of Sciences, P.O. Box 2871, Beijing 100085, P.R. China \\ ${ }^{2}$ Key Laboratory of Environmental Pollution Control Technology of Henan Province, Xinxiang, Henan 453002, \\ P.R. China \\ *Author for correspondence (Fax: +86-10-62923475; E-mail: yangmin@mail.rcees.ac.cn)
}

Received 21 January 2004; Revisions requested 4 February 2004; Revisions received 9 March 2004; Accepted 11 March 2004

Key words: cometabolism, degradation, polycyclic aromatic hydrocarbons, yeast

\begin{abstract}
Pichia anomala 2.2540, isolated from soil contaminated by crude oil, degraded naphthalene, dibenzothiophene, phenanthrene and chrysene, both singly and in combination. The yeast degraded $4.5 \mathrm{mg}$ naphthalene $1^{-1}$ within $24 \mathrm{~h}$. Phenanthrene was degraded after a lag of $24 \mathrm{~h}$. When a mixture of all four polycyclic aromatic hydrocarbons was treated at either $0.1-1.6 \mathrm{mg}^{-1}$ or $3.1-5.3 \mathrm{mg} \mathrm{l}^{-1}$, naphthalene was completely degraded first within $24 \mathrm{~h}$, followed by phenanthrene and dibenzothiophene after $48 \mathrm{~h}$. Chrysene, which remained in the mixture even after $96 \mathrm{~h}$, could be degraded along with naphthalene. Chrysene at 0.7 and $1 \mathrm{mg} \mathrm{l}^{-1}$, in the presence of 4.3 and $65 \mathrm{mg}$ naphthalene $\mathrm{l}^{-1}$, respectively, was removed within $96 \mathrm{~h}$.
\end{abstract}

\section{Introduction}

Polycyclic aromatic hydrocarbons (PAHs) are formed mainly during the incomplete combustion of organic material. They are also present in petroleum oil. The release of PAHs into the soil and water environments may pose a threat to food safety, as PAHs are recalcitrant and are potentially hazardous.

Many authors have studied PAH-degrading microorganisms usually using either co-metabolism or low PAH concentrations (Cerniglia 1992, Chaineau et al. 1995). However, some bacteria and fungi have been isolated that utilize PAHs as sole carbon and energy sources (Mueller et al. 1990, Romero et al. 1998).

In this study, Pichia anomala 2.2540 was isolated from soil contaminated by weathered crude oil. This yeast uses naphthalene and phenanthrene as sole carbon sources but also degrades dibenzothiophene and chrysene through co-metabolism. Here we report the degradation of these four PAHs, either singly or in combination.

\section{Materials and methods}

\section{Substrates}

The polycyclic aromatic hydrocarbons (PAHs) used in this study are given in Table 1. All were of the highest purity available (Acros Organic Co.).

\section{Isolation and identification of PAH-utilizing yeast}

Samples of soil contaminated with weathered crude oil were taken from Jidong Oilfield in Hebei Province, China. About $1 \mathrm{~g}$ soil was suspended in $10 \mathrm{ml}$ sterile water and added to a mineral basal salts (MBS) medium supplemented with $0.5 \%$ naphthalene at $27^{\circ} \mathrm{C}$ at $150 \mathrm{rpm}$ for 10 days. Yeast strains were isolated from MBS agar plates coated with naphthalene as the sole carbon source (Romero et al. 1998). The isolates were further transferred to phenanthrene-, dibenzothiophene- or chrysene-coated plates, respectively. The 26S rDNA D1/D2 domain sequence was determined to identify the yeast (Kurtzman \& Robnett 1998). 
Table 1. Properties of polycyclic aromatic hydrocarbons used in this study.

$\begin{array}{ll}\text { PAH } & \begin{array}{l}\text { Aqueous solubility } \\ \text { at } 25^{\circ} \mathrm{C}\left(\mathrm{mg} \mathrm{l}^{-1}\right)\end{array} \\ \text { Dibenzothiophene } & \end{array}$

\section{Degradation of PAHs in liquid cultures}

For each PAH, $100 \mathrm{mg}$ was dissolved in $10 \mathrm{ml}$ acetone, added to $50 \mathrm{~g}$ Tween $80 \mathrm{in} 50 \mathrm{ml}$ distilled water, ultrasonicated, and the suspension diluted with water to make $200 \mathrm{ml}$ (Andres et al. 1999).

In all experiments, $5 \mathrm{ml}$ batch cultures grown in $40 \mathrm{ml}$ sample tubes with screw caps and Teflon-lined septa. The isolate was pre-cultivated at $150 \mathrm{rpm}$ at $27^{\circ} \mathrm{C}$ in the following basal medium (BM): $\mathrm{KH}_{2} \mathrm{PO}_{4}$ $1 \mathrm{~g},\left(\mathrm{NH}_{4}\right)_{2} \mathrm{SO}_{4} 0.5 \mathrm{~g}, \mathrm{MgSO}_{4} \cdot 7 \mathrm{H}_{2} \mathrm{O} 0.5 \mathrm{~g}$, yeast extract $0.5 \mathrm{~g}$, distilled water $1000 \mathrm{ml}$, pH 5-6, supplemented with $10 \mathrm{~g}$ glucose (Yang et al. 2003). Cells were harvested by centrifugation, washed twice with sterile BM and inoculated into the modified BM supplemented with sole or mixtures of PAHs as the carbon source. The inoculum was controlled to approx. $2.4 \times 10^{8}$ cells $\mathrm{ml}^{-1}$. Heat-killed cells (autoclaved) and non-inoculated flasks were used as negative and blank controls. Cultures were grown in the dark with tumble-shaking at $150 \mathrm{rpm}$ and $27^{\circ} \mathrm{C}$ (McNally et al. 1999).

All experiments were run in triplicate.

\section{Analysis}

Five $\mathrm{ml}$ hexane was added to each culture, shaken horizontally for $2 \mathrm{~h}$ at $150 \mathrm{rpm}$ and approx. $2 \mathrm{ml}$ of the hexane layer was placed in an autosampler vial, crimpsealed with a Teflon-lined cap, then stored at $-20^{\circ} \mathrm{C}$ until analysis (Leblond et al. 2001). PAH concentrations were analyzed by gas chromatography interfaced

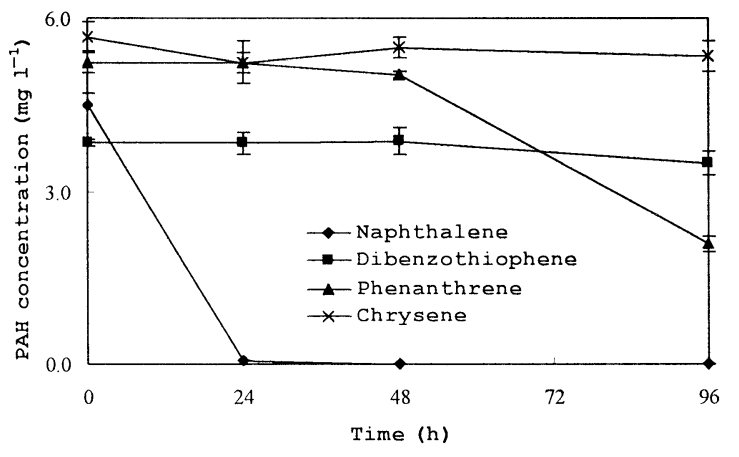

Fig. 1. Degradation of sole PAHs by P. anomala. The initial concentration of each PAH was: naphthalene, $4.5 \mathrm{mg} \mathrm{l}^{-1}$; dibenzothiophene, $3.8 \mathrm{mg} \mathrm{1}^{-1}$; phenanthrene, $5.2 \mathrm{mg} \mathrm{1}^{-1}$; chrysene, $5.7 \mathrm{mg} \mathrm{l}^{-1}$. Each point represents mean \pm S.E. of triplication.

with mass spectrometer detector (GC/MSD) in single ion monitoring (SIM) mode.

\section{Results and discussion}

\section{Isolation and identification of PAHs utilizing yeast}

Ten yeast strains were isolated from naphthalenecoated agar plates. One isolate, which rapidly degraded in liquid medium, was selected for further study. It could grow on agar plates coated with phenanthrene or dibenzothiophene but not on those coated with chrysene. The isolate has been lodged in the China General Microbiological Culture Collection Center (CGMCC) as CGMCC 2.2540. The BLAST search result through GenBank indicated that the D1/D2 sequence of this strain was identical to that of the type strain of Pichia anomala.

\section{Degradation of PAHs in liquid cultures}

Degradation of sole PAHs by P. anomala 2.2540 in liquid cultures is shown in Figure 1. A total of $3.1 \mathrm{mg}$ phenanthrene $1^{-1}$ was removed within $96 \mathrm{~h}$ following a lag time of $24 \mathrm{~h}$. No obvious degradation of dibenzothiophene and chrysene was detected over the cultivation period although the isolate could grow on agar plates coated with dibenzothiophene.

Figure 2 shows the results when $P$. anomala was grown in a mixture of four PAHs at two concentrations. The degradation of dibenzothiophene was observed at each concentration after $48 \mathrm{~h}$. The coexistence of naphthalene may be helpful for the degradation of dibenzothiophene. Two Pichia anomala strains have previously been reported to degrade the 

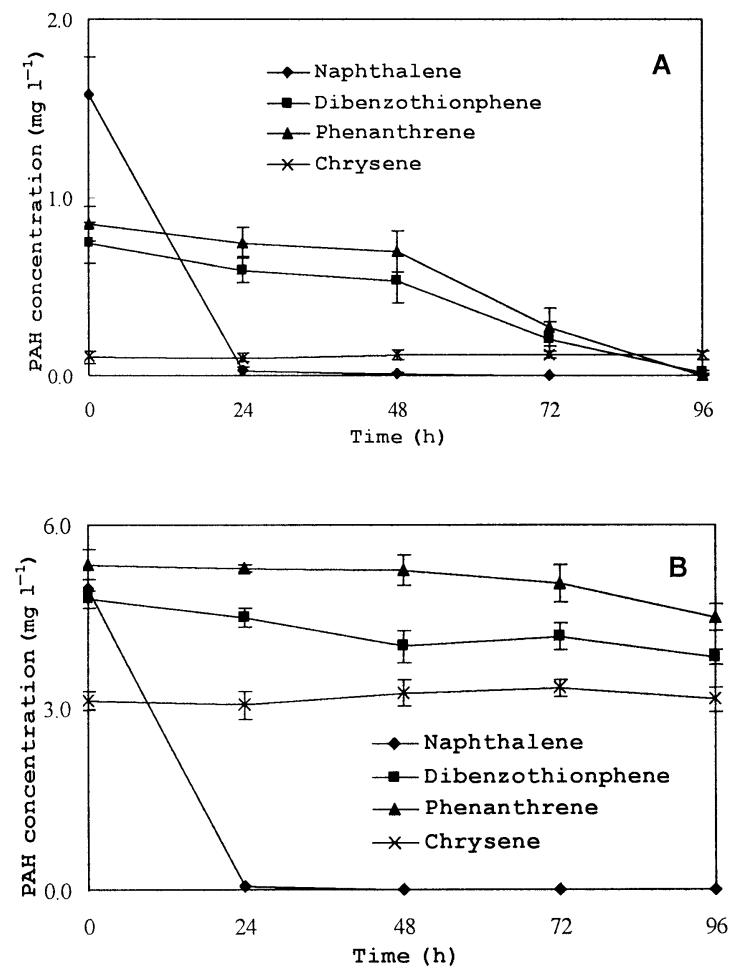

Fig. 2. Degradation of PAHs by $P$. anomala in mixture solutions at different concentrations. Initial concentrations of PAHs: (A) $0.1-1.6 \mathrm{mg} \mathrm{l}^{-1}$; (B) $3.1-5.3 \mathrm{mg} \mathrm{l}^{-1}$. Each point represents mean \pm S.E. of triplication.

biarylic compound, dibenzofuran, which has a structure similar to that of dibenzothiophene (Romero et al. 2002).

Figure $2 \mathrm{~A}$ shows that $0.8 \mathrm{mg}$ phenanthrene $\mathrm{l}^{-1}$ and $0.7 \mathrm{mg}$ dibenzothiophene $1^{-1}$ were completely degraded within $96 \mathrm{~h}$. Figure 2B shows that similar amounts of phenanthrene and dibenzothiophene were degraded within $96 \mathrm{~h}$ at higher substrate concentrations, indicating that the concentrations in this experiment were not a factor inhibiting PAH degradation. The degradation rate of phenanthrene in the combined PAH solutions, however, was lower than that in sole PAH solutions (Figure 1), indicating the possible occurrence of competitive inhibition between dibenzothiophene and phenanthrene. Chrysene could not be degraded over $96 \mathrm{~h}$ at either concentration.

Although chrysene was not degraded in the mixtures containing the four PAHs, it was significantly degraded when mixed with naphthalene only. With naphthalene at $4.3 \mathrm{mg} \mathrm{l}^{-1}, 0.7 \mathrm{mg}$ chrysene $\mathrm{l}^{-1}$ could be removed within $96 \mathrm{~h}$ after a lag time of $24 \mathrm{~h}$ (Figure $3 \mathrm{~A}$ ). However, with naphthalene at $64.7 \mathrm{mg} \mathrm{l}^{-1}$,
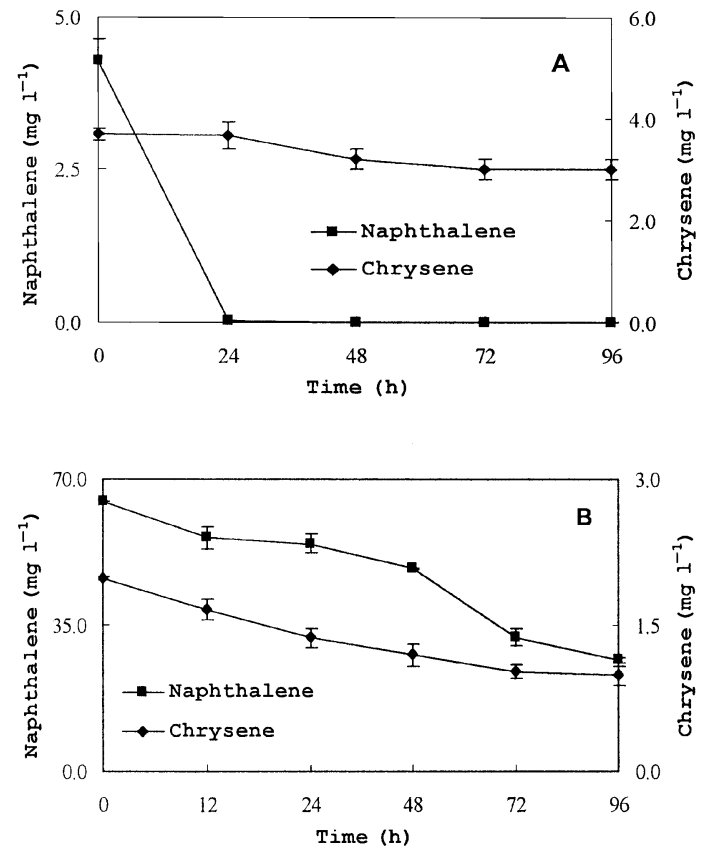

Fig. 3. Degradation of binary mixtures of naphthalene and chrysene by $P$. anomala at different naphthalene concentrations. (A) $4.3 \mathrm{mg} \mathrm{l}^{-1}$; (B) $64.7 \mathrm{mg} \mathrm{l}^{-1}$. Each point represents mean \pm S.E. of triplication.

no lag period was observed before the chrysene was degraded (Figure 3B) and $38 \mathrm{mg}$ naphthalene $1^{-1}$ and $1 \mathrm{mg}$ chrysene $\mathrm{l}^{-1}$ were removed within $96 \mathrm{~h}$. Chrysene was possibly being removed through a cometabolism mechanism.

A bacterium, Pseudomonas paucimobilis EPA505, which could utilize fluoranthene as the sole source of carbon and energy for growth, failed to grow in the saturated liquid culture of naphthalene (Mueller et al. 1990). Six PAH-degrading bacteria strains were isolated using six different PAHs as sole carbon and energy sources and naphthalene showed limited cometabolism capacities for other PAHs (fluorine, phenanthrene, anthracene, fluoranthene and pyrene) but was toxic to bacterial strains isolated on other compounds (Bouchez et al. 1995). In both cases, the high aqueous solubility of naphthalene (see Table 1) had apparently inhibited the growth of bacteria. In this present study, however, naphthalene as high as $64.7 \mathrm{mg} \mathrm{l}^{-1}$ did not inhibit $P$. anomala but promoted the degradation of chrysene. It is possible that naphthalene was inducing the enzymes required for the degradation of chrysene, and a higher enzyme concentration was produced under higher naphthalene concentration. The competitive inhibition between 
dibenzothiophene and chrysene may also explain why chrysene was not degraded in the mixtures of the four PAHs.

\section{Conclusion}

Pichia anomala degraded four PAHs, either through direct metabolism (for naphthalene and phenanthrene) or co-metabolism (for dibenzothiophene and chrysene). The isolate tolerated $65 \mathrm{mg}$ naphthalene $\mathrm{l}^{-1}$ and effectively degrade chrysene in the presence of naphthalene. Chrysene degradation, however, was not observed in solutions containing the above four PAHs over $96 \mathrm{~h}$.

\section{Acknowledgements}

This study was supported by the National Natural Science Foundation of China (No. 20337020), and the National Basic Research Program of China (No. 2003CB415006)

\section{References}

Andres S, Andrzej M, Christian J, Aloys H (1999) Degradation of fluorene, anthracene, phenanthrene, fluoranthene, and pyrene lacks connection to the production of extracellular enzymes by
Pleurotus ostreatus and Bjerkandera adusta. Intern. Biodeterior. Biodegrad. 43: 93-100.

Bouchez M, Blanchet D, Vandecasteele JP (1995) Degradation of polycyclic aromatic hydrocarbons by pure strains and by defined strain associations: inhibition phenomena and cometabolism. Appl. Microbiol. Biotechnol. 43: 156-164.

Cerniglia CE (1992) Biodegradation of polycyclic aromatic hydrocarbons. Biodegradation 3: 351-368.

Chaineau CH, Morel JL, Oudot J (1995) Microbial degradation in soil microcosms of fuel oil hydrocarbons from drilling cuttings. Environ. Sci. Technol. 29: 1615-1621.

Kurtzman CP, Robnett CJ (1998) Identification and phylogeny of ascomycetous yeasts from analysis of nuclear large subunit (26S) ribosomal DNA partial sequences. Ant. van. Leeuweenhoek 73: 331-371.

Leblond JD, Schultz TW, Sayler GS (2001) Observations on the preferential biodegradation of selected components of polyaromatic hydrocarbon mixtures. Chemosphere 42: 333-343.

McNally DL, Mihelcic JR, Lueking DR (1999) Biodegradation of mixtures of polycyclic aromatic hydrocarbons under aerobic and nitrate-reducing conditions. Chemosphere 38: 1313-1321.

Mueller JG, Chapman PJ, Blattmann BO, Pritchard PH (1990) Isolation and characterization of a fluoranthene-utilizing strain of Pseudomonas paucimobilis. Appl. Environ. Microbiol. 56: 1079-1086.

Romero MC, Cazau MC, Giorgieri S, Arambarri AM (1998) Phenanthrene degradation by microorganisms isolated from a contaminated stream. Environ. Pollut. 101: 355-359.

Romero MC, Hammer E, Cazau MC, Arambarri AM (2002) Isolation and characterization of biarylic structure-degrading yeasts: hydroxylation potential of dibenzofuran. Environ. Pollut. 118: 379-382.

Yang QX, Yang M, Pritsch K, Yediler A, Hagn A, Schloter M, Kettrup A (2003) Decolorization of synthetic dyes and production of manganese-dependent peroxidase by new fungal isolates. Biotechnol. Lett. 25: 709-713. 